\title{
CORRECTION
}

\section{Correction to: Rooted Spanning Superpixels}

\section{Dengfeng Chai ${ }^{1}$ (iD}

Published online: 16 October 2020

(c) Springer Science+Business Media, LLC, part of Springer Nature 2020

\section{Correction to: \\ International Journal of Computer Vision (2020) \\ 128:2962-2978 \\ https://doi.org/10.1007/s11263-020-01352-9}

The author regrets the omission of the following additional references to the International Journal of Computer Vision article, "Rooted Spanning Superpixels".

\section{References}

Alexandre, E. B., Chowdhury, A. S., Falcão, A. X., \& Miranda, P. A. V. (2015). IFT-SLIC: A general framework for superpixel generation based on simple linear iterative clustering and image foresting transform. In 2015 28th SIBGRAPI conference on graphics, patterns and images, Salvador (pp. 337-344). https://doi.org/10.110 9/sibgrapi.2015.20.
Vargas-Muñoz, J. E., Chowdhury, A. S., Alexandre, E. B., Galvão, F. L., Vechiatto Miranda, P. A., \& Falcão, A. X. (2019). An iterative spanning forest framework for superpixel segmentation. IEEE Transactions on Image Processing, 28(7), 3477-3489. https://doi. org/10.1109/TIP.2019.2897941.

Publisher's Note Springer Nature remains neutral with regard to jurisdictional claims in published maps and institutional affiliations.
The original article can be found online at https://doi.org/10.1007/s11 263-020-01352-9.

\section{Dengfeng Chai}

chaidf@zju.edu.cn

1 Key Laboratory of Geoscience Big Data and Deep Resource of Zhejiang Province, School of Earth Sciences, Zhejiang University, No. 38, Zheda Road, Hangzhou 310027,

Zhejiang, China 